\title{
Iraqi Women with Preeclampsia: Maternal and Neonatal Outcomes
}

\author{
Ban Abdulhameed Majeed ${ }^{1}$, Shaymaa Kadhim Jasim², Hayder Al-Momen ${ }^{1 *}$, Mohammed Jalal Hussein ${ }^{1}$ \\ ${ }^{1}$ Department of Pediatrics, Al-Kindy College of Medicine, University of Baghdad, Iraq; ${ }^{2}$ Department of Obstetrics and Gynecology, \\ College of Medicine, University of Baghdad, Iraq
}

Edited by: Ksenija Bogoeva-Kostovska Citation: Majeed BA, Jasim SK, Al-Momen H and Neonatal Outcomes. Open Access Maced $J$ Med Sci. 2020 Oct 15; 8(B):866-870 https://doi.org/10.3889/oamjms.2020.5043 Keywords: Cesarean section; Hypertension Low birth weight; Pregnancy weight gain; Preterm birth Correspondence: Hayder Al-Momen, Al-Nahda square, Al-Kindy College of Medicine, Baghdad, Iraq E-mail: hayder77almusawi@gmail.com Received: 03-Jun-2020 Revised: 24-Sep-2020 Copyright: ๑ 2020 Ban Abdulhameed Majeed, Shaymaa Kadhim Jasim, Hayder Al-Momen Funding: This research did not receive any financial Competing Interests: The authors have declared that no competing interests Open Access: This is an open-access article distribute under the terms of the Creative Commons Attribution-

\begin{abstract}
BACKGROUND: Preeclampsia (PE) is a possible etiology of obstetrical and neonatal complications which are increased in resource-limited settings and developing countries.

AIM: We aimed to find out the prevalence of PE in Iraqi ladies and specific outcomes, including gestational weight gain (GWG), cesarean section (CS), preterm delivery (PD), and low birth weight (LBW).

METHODS: All singleton pregnant women visiting our tertiary center for delivery were involved over 3 years. PE women were compared with non-PE ladies. Complete history and examination were done during pregnancy and after delivery by the attending obstetrician and neonatologist with full documentation in medical records.

RESULTS: PE prevalence was $4.79 \%$, and the affected women had significant $(p<0.05)$ higher age, body mass index, and GWG, but lower gestational age at delivery. The mean significant difference of GWG in PE and non-PE patients was $1.82 \mathrm{~kg}$. PD and LBW had significant higher frequencies in PE. After considering several confounding factors, crude and adjusted odds ratio (OR) of PE with $95 \%$ confidence interval $(95 \% \mathrm{Cl})$ were significant in CS (crude OR $=2.25$ and $95 \% \mathrm{Cl}=1.42-2.87$ while adjusted $\mathrm{OR}=2.89$ and $95 \% \mathrm{Cl}=1.43-3.06$ ) and $\mathrm{PD}$ (crude $\mathrm{OR}=2.41$ and $95 \% \mathrm{Cl}=1.73-2.46$ while adjusted $\mathrm{OR}=3.96$ and $95 \% \mathrm{Cl}=2.65-6.37$ ). On the other hand, only the crude model touched significance in LBW (crude OR $=3.67$ and $95 \% \mathrm{Cl}=2.51-4.99$ ).

CONCLUSIONS: Prevalence of PE in Iraqi pregnant females was higher than other neighboring developing countries. In PE ladies, maternal parameters, including GWG and operative delivery, and neonatal complications, including PD and LBW, were significantly higher than pregnant women without PE.
\end{abstract}

\section{Introduction}

Preeclampsia (PE) is a human phenomenon that occurred during pregnancy after 20 weeks of gestation and characterized by elevated blood pressure and presence of protein in urine. It carries a significant impact on maternal and neonatal health [1].

On an annual basis, it is estimated that PE results in up to one million maternal deaths and half a million fetal and early newborn deaths. PE affects people differently with various geographical locations ranging from $3 \%$ in the United States till $58 \%$ in Zimbabwe [2], [3], [4].

The abnormal placental tissue development is the main pathology behind PE especially if it occurred before 34 gestational weeks [5].

Many risk factors are associated with PE such as previous PE history, family history of pregnancy hypertensive disorders, multiple pregnancy, nullipara, advanced maternal weight and age, donor pregnancy (oocyte), and history of pre-pregnancy diabetes mellitus, hypertension, and renal disorders [6].
Exaggerated weight gain during pregnancy, increased risk of operative delivery, obstetrical bleeding problems, and increased maternal mortality are the main maternal PE complications, while fetal and neonatal adverse events include perinatal death, intrauterine growth limitation, and premature birth [7], [8].

Most papers concerned about PE came from high-income countries. In fact, some additional factors in low-income environments may affect PE and its adverse obstetrical and neonatal outcomes such as maternal anemia, recurrent infections, and poor education level [9], [10].

Insufficient health system in developing countries regarding prenatal care and absence of effective management plans of obstetrical diseases like PE may increase subsequent complications [11].

Therefore, we tried to conduct this study in a resource-limited setting in Iraq to explore the prevalence of $\mathrm{PE}$, in addition to certain maternal outcomes, including gestational weight gain (GWG) and operative delivery by cesarean section (CS), and neonatal outcomes, including preterm delivery (PD) and low birth weight (LBW). 


\section{Methods}

\section{Patients and basic characteristics}

This is a cross-sectional (population-based) study took place at the Center of Obstetrics and Gynecology in Medical City Hospital, Baghdad, Iraq, from the start of March 2017 till February 29, 2020. This tertiary hospital used to receive cases referred from various parts of the country, especially Baghdad which is the capital of Iraq.

All singleton pregnant ladies who had been diagnosed with PE visiting our center for delivery were involved and compared with healthy pregnant women without PE. Full medical history and examination, including body weight before pregnancy and at delivery, and the decision of delivery mode (vaginal or operative by CS) were made by the attending obstetrician and put down in the hospital files. The targeted neonatal outcomes (PD and LBW) were observed by the attending neonatologist and documented in the records.

\section{Definitions}

PE was diagnosed when blood pressure exceeded $140 / 90 \mathrm{mmHg}$ and presence of more than $0.3 \mathrm{~g} /$ day of urinary protein later in pregnancy after 20 weeks' gestation [12]. Body mass index (BMI) was estimated according to the following equation: Body weight $(\mathrm{kg}) /$ height $\left(\mathrm{m}^{2}\right)$ [13]. Delivery of a live neonate before full 37 gestational weeks was considered as PD [12]. LBW was concluded when it was $<2500 \mathrm{~g}$ at delivery [14].

Maternal age, parity, gravidity, occupation, educational status, pre-gestation BMI, previous abortions, and gestational age at delivery were considered as confounding factors that were adjusted using logistic regression analysis.

\section{Ethical approval}

All participants gave their consent to be part of this study which was conducted according to the Helsinki Declaration and approved by the ethical and scientific committees of the College of Medicine and Al-Kindy College of Medicine at University of Baghdad.

\section{Statistical analysis}

Stata statistical software (Stata Corp LP, College Station, TX Stata) was used to complete the statistical analysis. Frequencies (\%) represented categorical data, while continuous variables were presented as mean \pm standard deviation (SD). $p$ value (two-sided) $<0.05$ was assumed significant. The association between PE and the targeted outcomes of this study which were GWG, operative delivery by
$C S, P D$, and LBW was assessed using odds ratio $(\mathrm{OR})$ in crude and adjusted forms. Logistic regression approaches (univariate and multiple) were performed in the analysis. The fitness of models of logistic regression was examined through applying Akaike Information Criterion (AIC). The best model was accompanied with the lowest AIC [15].

\section{Results}

Of 24,783 total involved ladies, 1186 pregnant women had PE representing a prevalence of $4.97 \%$.

Table 1 shows the general characteristics of our sample of women with and without PE. Older mean age was significantly $(p<0.05)$ found in PE than non-PE women $(29.47 \pm 6.32$ years and $28.14 \pm 6.85$ years, respectively). PE ladies had significant lower gestational age at delivery. BMI before pregnancy was significantly higher in PE versus non-PE group $(29.05 \pm$ 6.11 vs. $26.34 \pm 5.63$ ) and GWG during pregnancy did the same $(13.67 \pm 5.81 \mathrm{~kg}$ vs. $11.44 \pm 4.79 \mathrm{~kg})$.

Table 1: General features of involved cases

\begin{tabular}{|c|c|c|c|}
\hline Maternal variable & $\begin{array}{l}\text { PE women, } \\
n=1186\end{array}$ & $\begin{array}{l}\text { Non-PE women, } \\
\mathrm{n}=24,783\end{array}$ & $\mathrm{p}$-value \\
\hline Age (years), mean $\pm S D$ & $29.47 \pm 6.32$ & $28.14 \pm 6.85$ & $<0.05$ \\
\hline Gravidity, mean $\pm S D$ & $4.67 \pm 2.74$ & $4.96 \pm 3.03$ & 0.72 \\
\hline Parity, mean \pm SD & $3.81 \pm 1.46$ & $3.6 \pm 1.57$ & 0.54 \\
\hline Previous spontaneous abortions, $\mathrm{n}(\%)$ & $0.89 \pm 0.57$ & $0.83 \pm 0.49$ & 0.26 \\
\hline \multicolumn{4}{|l|}{ Occupation, $\mathrm{n}(\%)$} \\
\hline Employed & 177 (14.92) & $3941(15.90)$ & 0.63 \\
\hline Housewife & $1009(85.08)$ & $20842(84.10)$ & \\
\hline \multicolumn{4}{|l|}{ Education, $\mathrm{n}(\%)$} \\
\hline Literate & $892(75.21)$ & $19089(77.02)$ & 0.38 \\
\hline Illiterate & $294(24.79)$ & $5694(22.98)$ & \\
\hline Pre-pregnancy BMI, mean \pm SD & $29.05 \pm 6.11$ & $26.34 \pm 5.63$ & $<0.05$ \\
\hline $\begin{array}{l}\text { Gestational age at delivery (weeks), } \\
\text { mean } \pm \text { SD }\end{array}$ & $36.52 \pm 3.45$ & $38.13 \pm 5.34$ & $<0.05$ \\
\hline GWG in $\mathrm{kg}$, mean $\pm \mathrm{SD}$ & $13.67 \pm 5.81$ & $11.44 \pm 4.79$ & $<0.05$ \\
\hline \multicolumn{4}{|l|}{ Mode of delivery, $n(\%)$} \\
\hline Vaginal & $240(20.24)$ & $11892(47.98)$ & $<0.05$ \\
\hline CS & $946(79.76)$ & $12891(52.02)$ & \\
\hline
\end{tabular}

Multiple logistic regression analysis was applied to adjust the confounding factors, including maternal age, parity, gravidity, previous spontaneous abortions, education, occupation, BMI (pre-pregnancy), and gestational age at delivery. The result revealed a mean difference of $(1.82 \mathrm{~kg})$ of GWG in PE and non-PE patients. Furthermore, mean GWG in PE pregnant ladies was significantly higher $(p<0.05)$ than non-PE women (difference mean $=1.82 \mathrm{~kg}, 95 \%$ confidence interval [Cl]: 0.69-13.21 kg)

PD was significantly occurred in a higher percentage in PE than non-PE patients $(232$ [19.56\%] vs. 2059 [8.31\%], respectively). This was also applied to LBW (193 [16.27\%] vs. 1273 [5.14\%], respectively), as illustrated in Table 2.

Table 2: Neonatal outcomes of PE and non-PE group

\begin{tabular}{llll}
\hline Outcome & PE women, $\mathrm{n}=1186$ & Non-PE women, $\mathrm{n}=24783$ & $\mathrm{p}$-value \\
\hline PD, $\mathrm{n}(\%)$ & $232(19.56)$ & $2059(8.31)$ & $<0.05$ \\
LBW, $\mathrm{n}(\%)$ & $193(16.27)$ & $1273(5.14)$ & $<0.05$ \\
\hline \multicolumn{2}{l}{ LBW: Low birth weight, PD: Preterm delivery. } & &
\end{tabular}


Crude and adjusted OR and $95 \% \mathrm{Cl}$ of CS and PD were appeared significant in PE group, while LBW showed significance in crude forms only of RR and $95 \%$ Cl. These are clear in Table 3.

Table 3: Relationship between PE and selective obstetrical and neonatal outcomes

\begin{tabular}{|c|c|c|c|c|c|c|}
\hline \multirow[t]{2}{*}{ Outcome } & Crude & Estimation & p-value & Adjusted & Estimation & p-value \\
\hline & $\overline{O R}$ & $95 \% \mathrm{Cl}$ & & $\overline{O R}$ & $95 \% \mathrm{Cl}$ & \\
\hline CS & 2.25 & $1.42-2.87$ & $<0.05$ & 2.89 & $1.43-3.06$ & $<0.05$ \\
\hline PD & 2.41 & $1.73-2.46$ & $<0.05$ & 3.96 & $2.65-6.37$ & $<0.05$ \\
\hline LBW & 3.67 & $2.51-4.99$ & $<0.05$ & 1.23 & $0.86-2.42$ & 0.49 \\
\hline
\end{tabular}

\section{Discussion}

The prevalence of PE in our sample was $4.79 \%$ which was higher than neighboring countries such as Iran (4\%) and Jordan (1.3\%) [16], [17]. Furthermore, our prevalence was further higher than other developing countries such as Angola (0.85\%) and Niger (1.08\%) [9] .

Higher prevalence rates than ours were found in Brazil (8.23\%), Mexico (7.29), and China (15\%) [9], [18].

These differences in prevalence rates might be to maternal anemia, recurrent infections, poor academic level, genetic causes, and racial backgrounds [9], [10].

Maternal age, pre-gravid BMI, and GWG were significantly high in Iraqi PE ladies in consistent with other published materials from the United States and China [19], [20], while some researchers said that larger GWG in PE pregnant women occurred only in singleton rather than twin pregnancies [21].

Here in this study, after adjustment of the above-mentioned confounding factors, mean GWG in $P E$ patients was higher $1.82 \mathrm{~kg}$ than healthy pregnant women (non-PE women) which was slightly higher than $1.77 \mathrm{~kg}$ found in Iran [22].

Operative delivery by CS was very evident in our PE ladies $(79.76 \%)$ in comparison to healthy pregnant ladies without PE (52.02\%). This is consistent with other Ecuadorian scientists who claimed a high rate of CS in PE women with even iatrogenic causes to decrease complications [23]. Our CS rate in the non-PE group was similar to the local CS prevalence in Iraqi pregnant ladies [24].

When controlling for the above-mentioned confounding risks, OR of operative delivery in our PE women was 3.96. This is much higher than the Iranian figure (1.92) [22].

$\mathrm{PD}$ prevalence reached significance in $\mathrm{PE}$ with $19.56 \%$ versus $8.31 \%$ in a healthy pregnancy (without PE) in our study with an adjusted OR of 2.89. In a previous study conducted in Jordan, PD rate was $30.8 \%$ during $\mathrm{PE}$ and $7 \%$ during uneventful pregnancy [17].

Our adjusted OR of PD in PE group after controlling for the confounding factors was 2.89 which was lower than 4.43 observed in Scotland [25] and 3.49 observed in Iran [26]. In Canada, the relative risk of PD during PE was 16.91, confirming the idea of higher frequencies of prematurity in PE patients [27].

In PE ladies of our sample, LBW was significantly high when compared with non-PE ladies ( $16.27 \%$ vs. $5.14 \%$, respectively). Further higher results were observed in Jordan, including $32.5 \%$ for PE and 8.3\% for non-PE females [17].

In general, LBW was reported by many precedent works to have a significant link with PE [28], [29].

On the contrary of other studied parameters in this study, adjusted OR of LBW in PE females was 1.23 but failed to touch significance, in contrast to 4.74 of a prior American study which was significant in the involved hyperthyroid pregnant ladies [30].

This study has the power of involving a large sized sample of pregnant women with or without PE over 3 years in a tertiary center of a developing country. Up to our knowledge, it is the biggest study done in Iraq and surrounding countries of the Middle East. Although assessing the effects of confounding factors is a powerful point, a bias of scanty data resulted from small-sized samples of some collections of exposure and outcome measurements could be considered as a limitation aspect of this study. Furthermore, diet policy consumed by recruited pregnant ladies as a confounding factor was not measured, and hemorrhagic obstetrical disorders (anti- and post-partum) as an important PE outcome were not analyzed and may be considered as limitation points.

\section{Conclusions}

Iraqi pregnant women had a higher prevalence of $\mathrm{PE}$ in comparison with some neighboring developing countries in the Middle East. Ladies diagnosed with $P E$ had significant complications in regard to maternal parameters (GWG and CS) and neonatal outcomes (PD and LBW). ORs of CS, PD, and LBW were significant in crude models and after controlling for confounding factors except in LBW, where the adjusted OR could not reach significance.

\section{Acknowledgments}

The authors would like to show their deep thanks to all medical and editorial staff in the involved center and all recruited pregnant ladies for their wonderful cooperation. 


\section{References}

1. Colvin ZA, Feng M, Pan AY, Palatnik A. 979: Duration of labor induction in nulliparous women with preeclampsia and maternal and neonatal outcomes. Am J Obstetr Gynecol. 2020;222(1):S608. https://doi.org/10.1016/j.ajog.2019.11.990

2. Ratsiatosika AT, Razafimanantsoa E, Andriantoky VB, Ravoavison N, Hery RA, Boukerrou M, et al. Incidence and natural history of preeclampsia/eclampsia at the university maternity of Antananarivo, Madagascar: High prevalence of the early-onset condition. J Matern Fetal Neonatal Med. 2019;32(19):3266-71. https://doi.org/10.1080/14767058.2018.1 462323

\section{PMid:29621911}

3. Ananth CV, Keyes KM, Wapner RJ. Pre-eclampsia rates in the United States, 1980-2010: Age-period-cohort analysis. BMJ. 2013;347:f6564. https://doi.org/10.1136/bmj.f6564

4. Ngwenya $S$, Jones $B$, Heazell AE, Mwembe D. Statistical risk prediction models for adverse maternal and neonatal outcomes in severe preeclampsia in a low-resource setting: Proposal for a single-centre cross-sectional study at Mpilo central hospital, Bulawayo, Zimbabwe. BMC Res Notes. 2019;12(1):500. https:// doi.org/10.1186/s13104-019-4539-y

PMid:31409378

5. Abdulshaheed NA, Al-Habib MF. Electron microscopic study of the effects of preeclampsia on the placental endothelial cells ultra structures during pregnancy. Al-Kindy Coll Med J. 2010;6(1):39-44.

6. Zoet GA, Koster MP, Velthuis BK, de Groot CJ, Maas AH, Fauser BC, et al. Determinants of future cardiovascular health in women with a history of preeclampsia. Maturitas. 2015;82(2):15361. https://doi.org/10.1016/j.maturitas.2015.07.004 PMid:26255680

7. Ton TG, Bennett MV, Incerti D, Peneva D, Druzin M, Stevens W, et al. Maternal and infant adverse outcomes associated with mild and severe preeclampsia during the first year after delivery in the United States. Am J Perinatol. 2020;37(4):398-408. https://doi.org/10.1055/s-0039-1679916

PMid:30780187

8. Weitzner O, Yagur Y, Weissbach T, Man El G, Biron-Shental T. Preeclampsia: Risk factors and neonatal outcomes associated with early-versus late-onset diseases. J Matern Fetal Neonatal Med. 2020;33(5):780-4. https://doi.org/10.1080/14767058.2018 .1500551

\section{PMid:30001660}

9. Ver Luanni Bilano EO, Ganchimeg T, Mori R, Souza JP. Risk factors of pre-eclampsia/eclampsia and its adverse outcomes in low-and middle-income countries: A WHO secondary analysis. PLoS One. 2014;9(3):e91198. https://doi.org/10.1371/journal. pone.0091198

PMid:24657964

10. Jasim SK, Al-Momen H, Al-Asadi F. Maternal anemia prevalence and subsequent neonatal complications in Iraq. Open Access Maced J Med Sci. 2020;8:71-5. https://doi.org/10.3889/ oamjms.2020.3593

11. Phoa KY, Chedraui P, Pérez-López FR, Wendte JF, Ghiabi S, Vrijkotte $\mathrm{T}$, et al. Perinatal outcome in singleton pregnancies complicated with preeclampsia and eclampsia in Ecuador. J Obstetr Gynaecol. 2016;36(5):581-4. https://doi.org/10.3109/01 443615.2015.1107532 PMid:26790539

12. Jasim SK, Al-Momen H, Al-Naddawi AM. Prediction of maternal diabetes and adverse neonatal outcome in normotensive pregnancy using serum uric acid. Int $\mathrm{J}$ Res Pharm Sci. 2019;10(4):3563-9. https://doi.org/10.26452/ijrps.v10i4.1736
13. Jasim SK, Al-Momen H, Majeed BA, Hussein MJ. Rate of fetal macrosomia with maternal and early neonatal complications in internally moved people affected by violence. Int J Med Res Health Sci. 2018;7(7):141-6.

14. Al-Momen $\mathrm{H}$, Muhammed MK, Alshaheen AA. Neonatal seizures in Iraq: Cause and outcome. Tohoku J Exp Med. 2018;246(4):245-9. https://doi.org/10.1620/tjem.246.245

15. Sakamoto $Y$, Ishiguro M, Kitagawa G. Akaike Information Criterion Statistics. Dordrecht, Netherlands: D. Reidel; 1986. p. 81.

16. Shahgheibi S, Rezaie M, Kamangar TM, Zarea S, Yousefi SR The effect of season on the prevalence of preeclampsia. J Clin Gynecol Obstetr. 2016;5(3):81-4. https://doi.org/10.14740/ jcgo408w

17. Khader YS, Batieha A, Al-Njadat RA, Hijazi SA. Preeclampsia in Jordan: Incidence, risk factors, and its associated maternal and neonatal outcomes. J Matern Fetal Neonatal Med. 2018;31(6):7706. https://doi.org/10.1080/14767058.2017.1297411 PMid:28274172

18. Ye C, Ruan Y, Zou L, Li G, Li C, Chen Y, et al. The 2011 survey on hypertensive disorders of pregnancy (HDP) in China: Prevalence, risk factors, complications, pregnancy and perinatal outcomes. PLoS One. 2014;9(6):e100180. https://doi. org/10.1371/journal.pone.0100180

PMid:24937406

19. Bokslag A, Teunissen PW, Franssen C, van Kesteren F, Kamp O, Ganzevoort W, et al. Effect of early-onset preeclampsia on cardiovascular risk in the fifth decade of life. Am J Obstetr Gynecol. 2017;216(5):523. https://doi.org/10.1016/j. ajog.2017.02.015 PMid:28209494

20. Shao Y, Qu J, Huang H, Mao B, Dai W, He X, et al. Pre-pregnancy $\mathrm{BMI}$, gestational weight gain and risk of preeclampsia: A birth cohort study in Lanzhou, China. BMC Pregnancy Childbirth. 2017;17(1):400. https://doi.org/10.1186/s12884-017-1567-2 PMid:29191156

21. Lucovnik M, Blickstein I, Verdenik I, Steblovnik L, Bregar AT, Tu $\mathrm{N}$. Impact of pre-gravid body mass index and body mass index change on preeclampsia and gestational diabetes in singleton and twin pregnancies. J Matern Fetal Neonatal Med. 2014;27(18):19014. https://doi.org/10.3109/14767058.2014.892069 PMid:24506066

22. Omani-Samani $R$, Ranjbaran $M$, Amini $P$, Esmailzadeh $A$, Sepidarkish M, Almasi-Hashiani A. Adverse maternal and neonatal outcomes in women with preeclampsia in Iran. J Matern Fetal Neonatal Med. 2019;32(2):212-6. https://doi.org/ 10.1080/14767058.2017.1376643

PMid:28871889

23. Parra-Pingel PE, Quisiguiña-Avellán LA, Hidalgo L, Chedraui $P$, Pérez-López FR. Pregnancy outcomes in younger and older adolescent mothers with severe preeclampsia. Adolesc Health Med Ther. 2017;8:81. https://doi.org/10.2147/ahmt.s131050 PMid:28652838

24. Jasim SK. Post cesarean section surgical site infection; incidence and risk factors. Int J Sci Res. 2017;6(7):1864-8. https://doi.org/10.21275/art20175750

25. Davies EL, Bell JS, Bhattacharya S. Preeclampsia and preterm delivery: A population-based case-control study. Hypertens Pregnancy. 2016;35(4):510-9. https://doi.org/10.1080/1064195 5.2016 .1190846

PMid:27322489

26. Maroufizadeh $S$, Bagheri LN, Almasi HA, Amini $P$, Esmaeilzadeh A, Navid B, et al. Prevalence of cesarean section and its related factors among primiparas in Tehran Province, Iran, in 2015. J Isfahan Med Sch 2017;35(423):303-9.

27. Ray JG, De Souza LR, Park AL, Connelly PW, Bujold E, 
Berger H. Preeclampsia and preterm birth associated with visceral adiposity in early pregnancy. J Obstetr Gynaecol Can. 2017;39(2):78-81. https://doi.org/10.1016/j.jogc.2016.10.007

PMid:27998690

28. Sherf Y, Sheiner E, Vardi IS, Sergienko R, Klein J, Bilenko N. Like mother like daughter: Low birth weight and preeclampsia tend to reoccur at the next generation. J Matern Fetal Neonatal Med. 2019;32(9):1478-84. https://doi.org/10.1080/14767058.20 17.1410124 PMid:29172830

29. Ekubagewargies DT, Kassie DG, Takele WW. Maternal HIV infection and preeclampsia increased risk of low birth weight among newborns delivered at university of Gondar specialized referral hospital, Northwest Ethiopia, 2017. Ital J Pediatr. 2019;45(1):7. https://doi.org/10.1186/s13052-019-0608-z PMid:30630512

30. Millar LK, Wing DA, Leung AS, Koonings PP, Montoro MN Mestman JH. Low birth weight and preeclampsia in pregnancies complicated by hyperthyroidism. Obstetr Gynecol. 1994;84(6):946-9. https://doi. org/10.1016/0020-7292(95)94890-r

PMid:7970474 